\title{
Birinci Düzey Travma Merkezinde Pediyatrik Servikal Travmaların Tedavisi
}

\author{
M. Özgür TAŞKAPILIOĞLU, Pınar ESER OCAK, Oğuz ALTUNYUVA, \\ Şeref DOĞAN
}

Bursa Uludağ Üniversitesi Tıp Fakültesi, Beyin ve Sinir Cerrahisi Anabilim Dalı, Bursa.

\begin{abstract}
ÖZET
Pediatrik spinal yaralanmalar nadir görülen bir durumdur ancak bu hastaların tedavileri ile ilgili kesinleşmiş kriterler ortaya konulamamıştır. Bu çalışmada kliniğimizde Ocak 2010- Aralık 2019 tarihleri arasında takip ve tedavi edilen pediatrik hastaların dosyaları retrospektif olarak incelenmiştir. Çalışmamıza 23 hasta dahil edilmiştir. Hastaların 15 (\%65.2) tanesi erkek, 8'i (\%34.7) kadındı. Olguların büyük çoğunluğunun etiyolojisinde düsme ve trafik kazası (\%73.9) vardı. 8 hastada fraktür, 11 hastada subluksasyon saptandı. Hastaların 17 tanesi konservatif olarak tedavi edilirken, 6 hasta cerrahi olarak tedavi edildi. Servikal spinal yaralanmalar çocukluk çağında tanı ve tedavi açısından özellik ve dikkat gerektiren bir durumdur. Bu durumun yönetiminde çocukluklar ile erişkinlerin arasındaki anatomik farkların iyi bilinmesi hayati önem taşır.
\end{abstract}

Anahtar Kelimeler: Servikal. Travma. Pediatri. Pediatrik spinal travma.

Treatment of Pediatric Cervical Trauma in the First Level Trauma Center

\begin{abstract}
Pediatric spinal injuries are rare conditions. Although there are many studies on this subject, certain criteria regarding the treatment of these patients have not been revealed. In this study, the files of pediatric patients who were followed up and treated in our clinic between January 2010 and December 2019 were analyzed retrospectively. 23 patients were included in our study. 15 (65.2\%) of the patients were male and 8 (34.7\%) were female. The vast majority of cases had a fall in etiology and a traffic accident (73.9\%). Fracture was detected in 8 patients and subluxation in 11 patients. 17 patients were treated conservatively, while 6 patients were treated surgically. Cervical spinal injuries are rare conditions that requires special attention in terms of diagnosis and treatment in childhood. In the management of this condition, it is vital to know the anatomical differences between childhoods and adults.
\end{abstract}

Key Words: Cervical. Trauma. C. Pediatric spinal trauma.

Travma çocukluk çağındaki en önemli ölüm sebebidir ${ }^{1}$. Vertebra kırıkları bu yaş grubundaki tüm travmaların \% 5.2'sini oluşturur ve ölümlerin \% 0.82 'sine neden olur ${ }^{1}$. Servikal yaralanmalar çocukluk travmalarının \%60-80'nini oluştururken bu oran erişkinlerde \%30-40'dır². Hasar kemik yaralanmasından daha

Geliş Tarihi: 13.Mayıs.2020

Kabul Tarihi: 02.Temmuz.2020

Dr. M. Özgür TAŞKAPILIOĞLU

Bursa Uludağ Üniversitesi Tıp Fakültesi,

Beyin ve Sinir Cerrahisi Anabilim Dalı,

Bursa.

Tel: 02242952722

E-posta: ozgurt@uludag.edu.tr

Yazarların ORCID ID Bilgisi:

M. Özgür TAŞKAPILIOĞLU: 0000-0001-5472-9065

Pınar ESER OCAK: 0000-0003-0132-9927

Oğuz ALTUNYUVA: 0000-0002-3450-0471

Şeref DOĞAN: 0000-0002-9733-241X çok ligaman hasarı sonucu oluşmaktadır. Nörolojik hasar gelişme riski ilk 8 yaşta spinal kord omurga tarafından yeteri kadar korunamadığından daha yüksektir ${ }^{3}$.

Çocukluk çağında ligamanlar, disk yapıları, çevre doku ve kaslar henüz gelişmediğinden travmaya karş1 daha esnektir. Çocuklardaki bu hipermobilite nedeni ile vertebra hasar olmadan hareket edebilir ${ }^{3}$. Küçük çocuklarda travmadan üst servikal bölge etkilenirken; çocuklar büyüdükçe, omurga ve çevreleyen yapılar daha katı hale gelir; bu nedenle de erişkin hastalarda olduğu gibi büyük çocuklarda alt servikal bölge yaralanmaları sıktır.

Bu çalışmanın amacı, birinci düzey travma merkezinde çocukluk çağı servikal bölge patolojisi nedeni ile takip ve tedavi edilen hastaların epidemiyolojileri, risk faktörleri, preoperatif muayeneleri, tedavileri ve postoperatif takipleri açısından incelenmeleridir. 


\section{Gereç ve Yöntem}

Bursa Uludağ Üniversitesi Tıp Fakültesi klinik araştırmalar etik kurulunun onayı alındıktan sonra (20207/6) Beyin ve Sinir Cerrahisi kliniğinde Ocak 2010Aralık 2019 tarihleri arasında takip ve tedavi edilen pediatrik hastaların dosyaları retrospektif olarak incelenmiştir. Tüm çocukluk çağı servikal travmaları nörolojik defisit olup olmadığına bakılmaksızın çalışmaya dahil edilmiştir. Tedavi planı hastaya göre düzenlenmiştir.

Servikal bölgedeki yaralanmalar hastanın klinik durumuna göre direkt grafi, bilgisayarlı tomografi (BT) veya manyetik rezonans görüntüleme (MRG) ile değerlendirilmiştir.

Hasarın mekanizması, hastaların nörolojik muayeneleri, radyolojik bulgular, tedavi stratejileri ve takip sonuçları incelenmiştir. Hastalar ameliyattan sonra 15 gün, 1 ay, 3 ay, 6 ay ve 1 yıl sonra kontrollere çağırılmışlardır. 1 yıldan sonra hastalar yıllık olarak takip edilmeye devam edilmişlerdir. Takipten çıkan hastalar çalışmaya dahil edilmemiştir.

Bu çalışmaya 0-14 yaş arasındaki hastalar dahil edilmiştir. 15 yaş ve üzerinde kemik yapısı ve kaslar erişkin dönemdeki halini aldığından bu hastalar çalışma dışı bırakılmıştır; ayrıca doğuma bağlı yaralanmalar da çalışmaya dahil edilmemiştir. Radyolojik anormallik olmadan spinal kord yaralanması çocukluk çağında sık izlenmekle beraber bu çalışmanın konusu olmad1ğından bu hastalar çalışmaya dahil edilmemiştir.

Nicel veriler ortalama, standart sapma ve aralık olarak belirtilmiştir. Kalitatif veriler yüzde olarak belirtilmiştir.

\section{Bulgular}

Çalışmamıza 23 hasta dahil edilmiştir. Hastaların 15 (\%65.2) tanesi erkek, 8'i (\%34.7) kadındı. Hastaların yaşlarının ortalaması $8.7 \pm 3.5$ (min 2, maks 14) idi. Olguların büyük çoğunluğunun etiyolojisinde düşme ve trafik kazası (\%73.9) vardı (Tablo I). 6 hastanın preoperatif dönemde nörolojik defisiti mevcuttu. 8 hastada fraktür, 11 hastada subluksasyon saptandi. Hastaların 17 tanesi konservatif olarak tedavi edilirken, 6 hasta cerrahi olarak tedavi edildi (Şekil 1). 20 hastada patoloji C5 seviyesinin üzerinde idi. Hemiparezi saptanan 2 olgu ve tetraplejik olan 4 hastaya stabilizasyon operasyonu gerçekleştirildi. Santral kord sendromu saptanan bir olgu konservatif olarak tedavi edildi.

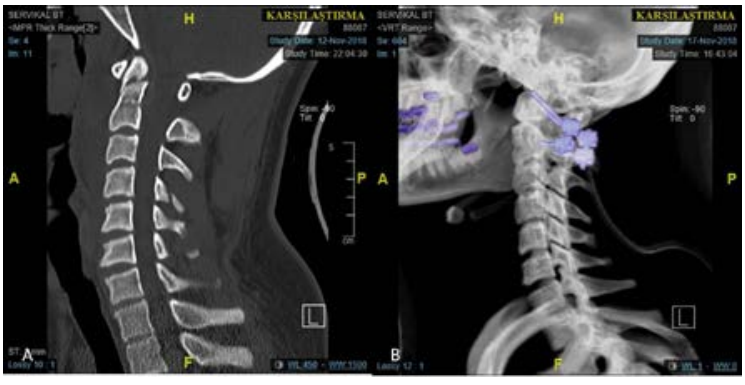

Şekil 1.

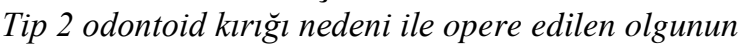
A preoperative ve B postoperative BT görüntüleri

Tablo I. Hastaların demografik özellikleri

\begin{tabular}{|c|c|c|c|c|c|}
\hline cinsiyet & yaş & etiyoloji & $\begin{array}{l}\text { nörolojik } \\
\text { muayene }\end{array}$ & patoloji & tedavi \\
\hline e & 14 & düşme & defisit yok & $\begin{array}{c}\text { C7 kompres- } \\
\text { yon }\end{array}$ & konservatif \\
\hline e & 14 & düşme & tetraplejik & \begin{tabular}{|c|}
$\begin{array}{c}\text { C4-5 dislokas- } \\
\text { yon }\end{array}$ \\
\end{tabular} & cerrahi \\
\hline e & 14 & düşme & defisit yok & $\begin{array}{c}\text { C1-2 dislokas- } \\
\text { yon }\end{array}$ & konservatif \\
\hline $\mathrm{e}$ & 2 & düşme & defisit yok & kondil kırığı & konservatif \\
\hline $\mathrm{e}$ & 7 & düşme & defisit yok & ligaman hasarı & konservatif \\
\hline e & 10 & bisiklet kazası & defisit yok & $\begin{array}{c}\text { C2-3 ligaman } \\
\text { hasarı }\end{array}$ & konservatif \\
\hline e & 13 & bisiklet kazası & defisit yok & $\begin{array}{c}\text { C2-3 ligaman } \\
\text { hasarı }\end{array}$ & konservatif \\
\hline k & 7 & düşme & defisit yok & \begin{tabular}{|c|} 
tip 1 odontoid \\
kırığı
\end{tabular} & konservatif \\
\hline k & 7 & düşme & defisit yok & C2-3 listezis & konservatif \\
\hline e & 9 & trafik kazası & $\begin{array}{c}\text { Sağda } 1 / 5 \\
\text { def+spasti } \\
\text { site }\end{array}$ & \begin{tabular}{|c|} 
Odontoid \\
proçeste ters \\
açılanma \\
\end{tabular} & cerrahi \\
\hline k & 9 & düşme & defisit yok & $\begin{array}{l}\text { Atlantoaksiyal } \\
\text { subluksasyon }\end{array}$ & konservatif \\
\hline k & 5 & trafik kazası & defisit yok & $\begin{array}{l}\text { C1-2 dislokas- } \\
\text { yon+C1 kırığı }\end{array}$ & konservatif \\
\hline k & 5 & darp & defisit yok & C1 arkus kırığı & konservatif \\
\hline k & 4 & trafik kazası & defisit yok & $\begin{array}{c}\text { Atlantoaksiyal } \\
\text { dislokasyon }\end{array}$ & konservatif \\
\hline e & 7 & darp & defisit yok & $\begin{array}{c}\text { Atlantoaksiyal } \\
\text { dislokasyon }\end{array}$ & konservatif \\
\hline k & 10 & düşme & $\begin{array}{l}\text { Üstte plejik } \\
\text { altta } 3 / 5 \\
\text { kas gücü } \\
\end{array}$ & $\begin{array}{l}\text { C2 ligaman } \\
\text { hasarı }\end{array}$ & konservatif \\
\hline e & 8 & düşme & defisit yok & $\begin{array}{l}\text { C2-3 subluk- } \\
\text { sasyon ve } \\
\text { dens kırığı }\end{array}$ & konservatif \\
\hline e & 10 & trafik kazası & \begin{tabular}{|c|} 
sağda \\
hemipare- \\
zik \\
\end{tabular} & $\begin{array}{c}\text { C3-4 ligaman } \\
\text { hasarı }\end{array}$ & cerrahi \\
\hline e & 5 & trafik kazası & $\begin{array}{l}\text { tetrapare- } \\
\text { tik }\end{array}$ & \begin{tabular}{|c|} 
tip 1 odontoid \\
kırı̆ı̆ C3-4 \\
spondiloliste- \\
zis \\
\end{tabular} & cerrahi \\
\hline k & 9 & trafik kazası & defisit yok & $\begin{array}{c}\text { C7 çökme } \\
\text { kırı̆̆ı }\end{array}$ & cerrahi \\
\hline e & 10 & darp & defisit yok & $\begin{array}{c}\text { Atlantoaksiyal } \\
\text { dislokasyon } \\
\end{array}$ & konservatif \\
\hline e & 14 & darp & defisit yok & \begin{tabular}{|c|}
$\begin{array}{c}\text { C1-2 dislokas- } \\
\text { yon }\end{array}$ \\
\end{tabular} & konservatif \\
\hline e & 14 & düşme & tetraplejik & $\begin{array}{c}\text { C3-4, C4-5 } \\
\text { spondiloliste- } \\
\text { zis }\end{array}$ & cerrahi \\
\hline
\end{tabular}




\section{Tartışma ve Sonuç}

Çocukluk çağı spinal yaralanmaları; özellikle servikal bölge travmalarının yönetimi hakkına çok çalışma olmasına rağmen bu fikir birliğine varılmamış bir konudur.

Yeteri kadar gelişmemiş kaslar, kıkırdak son plaklar, sığ ve yatay faset eklemler, kalsifikasyonunu tamamlamamış kama şeklinde vertebra korpusları, az elastik diskler, elastik eklem kapsülleri ve ligamanlar, vücuda oranla daha büyük kafa yapısı nedeni ile çocukluk çağında servikal yaralanma oranı erişkinlere oranla daha yüksektir ${ }^{5}$. Servikal yaralanmalar erișkin popülasyonda olduğu gibi erkeklerde kadınlardan daha sık 1.5-2.1:1 izlenir ${ }^{6}$. Olgularımızın \%65.2 si literatürle uyumlu olarak erkek idi.

Erken çocukluk döneminde yaralanmanın sıklıkla sebebi düşme ve araç dişı travmalar iken, daha büyük yaşlarda trafik kazaları ve spor yaralanmaları en sık nedenlerdir ${ }^{4}$. Bizim serimizde en sik sebep literatürle uyumlu olarak düşme ve trafik kazası olarak saptanmıştır. Spor kazasının hiç görülmemesini sosyoekonomik şartlara bağlanabilirken bu başlık altında değerlendirilebilecek bisiklet kazaları 3 olguda izlenmiştir.

Çocuklarda erişkinlere oranla travma sonrası nörolojik defisit daha az görülmektedir ${ }^{7}$. Serimizde hastaların nörolojik muayeneleri değerlendirildiğinde olguların çoğunda ${ }^{6 / 23}$ preoperatif nörolojik defisit yok idi. Bu olgulardan santral kord sendromu izlenen hasta dışındaki tüm olgulara stabilizasyon operasyonu uygulandı.

Çocukluk çağında spinal travma hastalarında tanı konulmasında hastanın kendini yeteri kadar ifade edememesine bağlı güçlükler vardır. Direkt grafilerde fraktür hattı, subluksasyon tespit edilebilir. Küçük çocuklarda grafilerin hem çekilmesi hem de değerlendirilmesi zorluk gösterebilir. Direkt grafilerde \%32 oranında tanı konulmasında başarısızlık bildirilmiştir ${ }^{8}$. BT direkt grafilere göre daha detaylı bilgi verir. Avellino ve ark sevikal bölge patolojilerinde tanı konulmasındaki hatanın çocuklarda \%5'e kadar çıkabildiğini belirtmişlerdir ${ }^{9}$. Literatürde kullanılacak görüntüleme yöntemi hakkında fikir birliği yoktur ${ }^{10}$. Çocuklarda radyasyona maruziyetin hayatın ilerleyen zamanlarında kanser gelişme riskini arttırdığı unutulmamalıdır ${ }^{11}$. MRG özellikle nörolojik defisit tespit edilen hastalarda mutlaka görülmesi gerekir ve çocukluk çağında sık görülen ligaman yaralanması tanısında altın standarttır. Radyolojik görüntüler değerlendirilirken hastaların yaşı ve omurgada büyüme sırasında görülen değişiklikler akılda tutulmalıdır. Çocuklarda erişkinlerdeki gibi aterosklerotik değişiklikler olmamakla beraber servikal travmalarda kraniyoservikal arteriyel diseksiyon açısından dikkatli olunmalıdır. Serimizde ligaman hasarı düşünülen ve nörolojik defisiti olan olgular dışındaki hastalar acil serviste öncelikle direkt grafi ile değerlendirilmiş; patoloji saptanan hastalar servikal BT ile görüntülenmişlerdir.

Elastik yapısı nedeni ile çocuklarda servikal bölgenin stabilize edilmesi çok daha güçtür. Kolora rağmen özellikle üst servikal bölgede tam bir stabilite sağlanması zordur. Halo kullanılması psikososyal yan etkilerinin yanında dural penetrasyon, supraorbital sinir yaralanması gibi olası komplikasyonları nedeni ile tercih edilmemektedir ${ }^{12}$. Cerrahi fiksasyon, stabilitenin sağlanması ve spinal kordu hasardan korumak için önemlidir. Stabilizasyonun genel prensipleri erişkinler ile aynı olmakla beraber ameliyat planlanırken hastanın büyüme potansiyeli ve yapılacak işlemin omurganın eğriliğine olan etkisi göz önüne alınmalıdır. Serimizde ligaman hasarı olan hastalar konservatif olarak tedavi edilmiştir. Servikal kolor ile takip edilen hastaların tedavileri poliklinik takiplerinde stabilitenin sağlandığına emin olunduktan sonra sonlandırılmıştır.

Üst servikal bölge yaralanmalarında mortalite \%33 düzeyinde iken alt servikal bölge yaralanmalarında bu oran \%8.3'tür ${ }^{13}$. Çok merkezli bir çalışmada, Geuther ve ark adolesanlar ile erişkin hastalar arasında servikal travmadan sonra fonksiyonel iyileşme açısından fark bulamaz iken, juvenil yaş grubundaki hastalarda sonuçlar daha iyi bulunmuştur ${ }^{13}$. Bu çalışmaya dahil edilen hastalarda mortalite izlenmez iken nörolojik defisiti olan hastalarda yattıkları süreçte ve poliklinik takiplerinde fonksiyonel iyileşme saptanamamıştır.

Postoperatif dönemde hastalar komplikasyonlar açısindan takip edilmelidir. Uzun dönem takip normal büyümenin izlenmesi açısından hayatidir.

Servikal spinal yaralanmalar çocukluk çağında tanı ve tedavi açısından özellik ve dikkat gerektiren bir durumdur. Bu durumun yönetiminde çocukluklar ile erişkinlerin arasındaki anatomik farkların iyi bilinmesi hayati önem taşır.

\section{Etik Kurul Onay Bilgisi:}

Onaylayan Kurul: Uludağ Üniversitesi Tıp Fakültesi Klinik Araştırmalar Etik Kurulu.

Onay Tarihi: 29.04 .2020

Karar No: 2020-7/6

\section{Kaynaklar}

1. Galano GJ, Vitale MA, Kessler MW, Hyman JE, Vitale MG. The most frequent traumatic orthopaedic injuries from a national pediatric inpatient population. J Pediatr Orthop 2005; 2: 3944.

2. Eubanks JD, Gilmore A, Bess S, Cooperman DR. Clearing the pediatric cervical spine following injury. J Am Acad Orthop Surg. 2006;14(9):552-564.

3. Pang D. Spinal cord injuries. McLone DG (ed), Pediatric Neurosurgery, $4^{\text {th }}$ ed, Philadelphia: WB Saunders, 2001: 660694

4. Jain A, Brooks JT, Rao SS, Ain MC, Sponseller PD. Cervical fractures with associated spinal cord injury in children and ado- 


\section{M.Ö. Taşkapılığlu, ark.}

lescents: epidemiology, costs, and in-hospital mortality rates in 4418 patients. J Child Orthop 2015; 9: 171-175.

5. Hakan Karabağlı Omurga yaralanmaları ve tedavisi Pediatrik Nöroşirurji Ed: Baykaner K, Erşahin Y, Mutluer S, Özek M Türk Nöroşirurji Derneği yayınları Ankara 755-766

6. Baumann F, Ernstberger T, Neumann C, Nerlich M, Schroeder GD, Vaccaro AR, Loibl M. Pediatric cervical spine injuries: a rare but challenging entity. $\mathrm{J}$ Spinal Disord Tech. 2015;28(7):E377-384.

7. Patel JC, Tepas JJ III, Mollitt DL, Pieper P. Pediatric cervica spine injuries: defining the disease. J Pediatr Surg. 2001;36(2):373-376.

8. Hale AT, Alvarado A, Bey AK, Pruthi S, Mencio GA, Bonfield CM, Martus JE, Naftel RP. X-ray vs. CT in identifying significant C-spine injuries in the pediatric population. Childs Nerv Syst. 2017;33(11):1977-1983

9. Avellino AM, Mann FA, Grady MS, Chapman JR, Ellenbogen RG, Alden TD, Mirza SK. The misdiagnosis of acute cervical spine injuries and fractures in infants and children: the 12-year experience of a level I pediatric and adult trauma center. Childs Nerv Syst. 2005;21(2):122-127.
10. Herman MJ, Brown KO, Sponseller PD, Phillips JH, Petrucelli PM, Parikh DJ, Mody KS, Leonard JC, Moront M, Brockmeyer DL, Anderson RCE, Alder AC, Anderson JT, Bernstein RM, Booth TN, Braga BP, Cahill PJ, Joglar JM, Martus JE, Nesiama JO, Pahys JM, Rathjen KE, Riccio AI, Schulz JF, Stans AA, Shah MI, Warner WC Jr, Yaszay B. Pediatric Cervical Spine Clearance: A Consensus Statement and Algorithm from the Pediatric Cervical Spine Clearance Working Group. J Bone Joint Surg Am. 2019;101(1):e1.

11. Brenner DJ, Hall EJ. Computed tomography-an increasing source of radiation exposure. $N$ Engl $J$ Med. 2007;357(22):2277-2284.

12. Copley PC, Tilliridou V, Kirby A, Jones J, Kandasamy J. Management of cervical spine trauma in children. Eur J Trauma Emerg Surg. 2019;45(5):777-789

13. Geuther M, Grassner L, Mach O, Klein B, Högel F, Voth M, Bühren V, Maier D, Abel R, Weidner N, Rupp R, Fürstenberg $\mathrm{CH}$; EMSCI study group, Schneidmueller D. Functional outcome after traumatic cervical spinal cord injury is superior in adolescents compared to adults. Eur J Paediatr Neurol. 2019;23(2):248-253. 